\title{
The Economics Of Bidding In Project Management
}

A. M. Alli, Oklahoma City University, USA

David L. May, Oklahoma City University, USA

\begin{abstract}
This article develops strategic decision tables to be used by management in bidding based on optimal duration costs. In addition, a process is proposed to find the optimal economic duration of the project using crashing techniques, the simplex method of linear programming, and game theory. Standardized software packages for Decision Support Systems (DSS) are used in facilitating the calculations.
\end{abstract}

Keywords: Bidding, Project Management, Linear Programming, Decision Support Systems

\section{INTRODUCTION}

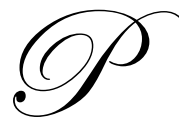

roject Management is a very useful tool to plan, schedule and control projects. Projects can be configured as networks with a start, intermediate activities with dependencies among the activities, and an end. The Critical Path Method (CPM) and the Program Evaluation and Review Technique (PERT) are two methods to analyze the networks. CPM and PERT are the basis on which software packages, called Decision Support Systems (DSS), are developed. The software packages are generally used to identify the critical path and its duration. In addition, the DSS will calculate the earliest start and finish times, the latest start and finish times, and the slack time for each given activity in the project. If the DSS has graphical capability, it can draw the program's network. Some DSS offer accounting sheets, which summarize cost information. Functionality of any given DSS is dependent upon its design features. All DSS will generally facilitate scheduling of the activities and identifying the duration of project completion time. Through the use of Program Management software and the simplex method of Linear Programming, the cost of the project, as a function of its duration, can be calculated using individual activity duration crashing techniques.

Our premise is that by using time analysis and crashing to the project duration lower limit with DSS packages, the decision maker is able to add the burden cost to the direct cost. The decision-maker can then choose the total minimum cost duration rather than critical path duration in scheduling the activities of the project. This paper deals with this phase of the analysis using software packages Quantitative Management (QM) and Decision Support Systems for Management Science/Operations Research (DSS_MSOR). In addition, the decision maker is able to prepare the total cost decision table from which the cost is a function of project duration, including the burden cost plus crashing cost and normal costs. The developed decision tables in this article are useful tools in bidding on competitive projects in different sectors of the market and they are the focus of this article. Game theory is used at this phase of the analysis to find the bidding strategies.

Shown below is a flowchart (Figure 1) and a procedure to be followed to build the strategic decision tables, the project activity schedule, the bar chart of the project activities, and the cost analysis. A new DSS package is proposed with this functionality. The illustration given in this paper will demonstrate the input data required for the proposed package. The output of the illustration was run on different packages as subroutines in the proposed package. 


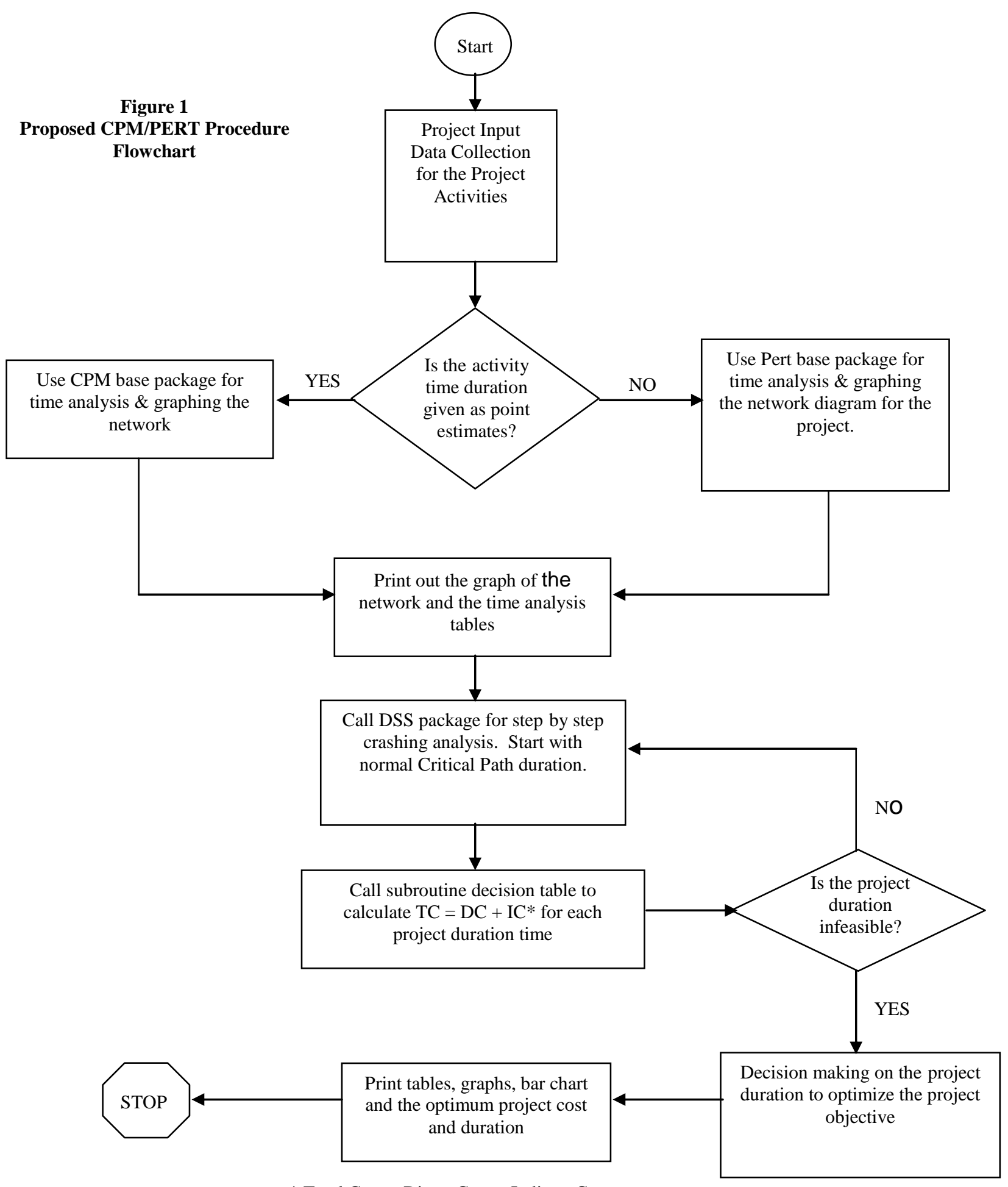

$*$ Total Cost $=$ Direct Cost + Indirect Cost 


\section{PROPOSED PROJECT MANAGEMENT PROCEDURE}

1 - List the activities that make up the project.

2 - List the immediate predecessors for each activity in the project.

3 - List the duration time(s) of each activity in the project.

- If the activity's duration time is given as point estimate, it goes directly to CPM time analysis routine.

- If the activity's duration times are given as $\mathrm{t}_{\mathrm{o}}, \mathrm{t}_{\mathrm{m}}, \mathrm{t}_{\mathrm{p}}$

$$
\text { Where: } \begin{aligned}
t_{\mathrm{o}} & =\text { optimistic time } \\
\mathrm{t}_{\mathrm{m}} & =\text { most likely time } \\
\mathrm{t}_{\mathrm{p}} & =\text { pessimistic time }
\end{aligned}
$$

They should be converted to expected time, $t_{e}$, and variance, $\square^{\square} \square$ of the activity package using the formulas below before using the time analysis.

$$
\begin{gathered}
t_{e}=\frac{t_{o}+4 t_{m}+t_{p}}{6} \\
\sigma^{2}=\left(\frac{t_{p}-t_{o}}{6}\right)^{2}
\end{gathered}
$$

The shape of the activity's time distribution is assumed to be normal.

4 - Draw the project network diagram depicting the activities and their immediate predecessors listed in steps (1) and (2).

5 - Use the project network package to determine the total time required to complete the project, the activities' earliest start and finish times, the activities' latest start and finish time, and the activities' slack times, if any.

6 - Define the project critical path and its duration from those project activities with zero slack times where they form a continuous chain form the starting node to the project's ending node.

7 - Develop the project activities schedule using the information prepared in step (5).

8 - Using the listed information about the activities' normal and crash times and normal and crash costs given in step (3), calculate the duration project costs by reducing the normal critical path by a known decrement of time, $-\Delta \mathrm{t}$. Start with the normal project duration calculated in step (6) and stop when the reduced project duration becomes infeasible to obtain. This would be done using a developed simplex model of Linear Programming for the project.

9 - Prepare a total cost-duration table containing direct total cost, indirect total cost, and the combined total cost with reference to the project duration time.

10 - Decide on the optimum total cost project duration with reference to the project objective function given in step (8). 


\section{STRATEGIC TABLES DEVELOPMENT}

Let:

DDP/L $(i, j)=$ Duration differential Profit / Loss at row i planned project duration and column $\mathrm{j}$ contract's project duration

PPD(i) $\quad=$ Planned project duration of row $\mathrm{i}$

$\mathrm{CPD}(\mathrm{j}) \quad=$ Contract's project duration of column $\mathrm{j}$

PPDC(i) = Planned project duration cost of row $\mathrm{i}$

$\mathrm{CPDC}(\mathrm{j})=$ Contract's project duration of column $\mathrm{j}$

Then:

$\operatorname{DDP} / \mathrm{L}(\mathrm{i}, \mathrm{j})=\operatorname{CPDC}(\mathrm{J})-\operatorname{PPDC}(\mathrm{i}) \quad \mathrm{i}=1,2,3, \ldots \ldots \mathrm{m}, \mathrm{J}=1,2,3, \ldots . \mathrm{n}$

Where $m=$ No. of rows,$\& n=$ No. of columns in DDP/L $(i, j)$ matrix.

The positive DDP/L (i, j) are benefit to the bidder if the CPD (j) shifted to PPD (i). The negative DDP/L (i, j) are losses to the bidder if the CPD (j) shifted to PPL (i) (see Table 1). DDP/L (i, j) is the maximum amount the bidder is willing to pay to shift the CPD (j) to PPD (i). The negative DDP/L (i, j) will not be considered (see Table 2), due to the fact that there are losses that will be deducted from the markup profit. Table 3 gives the priorities in descending order of the positive DDP/L ( $\mathrm{i} \mathrm{j}$ ). These three tables play a vital role in the bidding game.

According to game theory, Table 4 shows the payoff value, DDP/L (i,j), if the bidder chooses PPD ( $i$ ) and the contract 's owner prefers CPD $(\mathrm{j})$. Assuming Table 1 is known to both parties, the optimal strategy is that the contract's owner chooses the minmax CPD (j) value according to:

$\operatorname{CPD}(j)=\operatorname{Min}_{j} .\left\{\operatorname{Max}_{i} . \operatorname{DDP} / L(i, j)\right\} \quad$ where $i=1,2, \ldots . . m, j=1,2 \ldots . . n$. and the bidder chooses the maxmin PPD (i) value according to:

$\operatorname{PPD}(i, j)=\operatorname{Max}_{i} \cdot\left\{\operatorname{Min}_{j} .(\operatorname{DDP} / L(i, j)\} \quad\right.$ where $i=1,2, \ldots m, j=1, \ldots . n$.

Game theory is used to determine the best strategy for both parties depending on whether the game is a mixed or a pure strategy game. By submitting Table 4 (seen on page 9 following the computer's game theory package), the output will show the best combination of $\operatorname{PPD}(\mathrm{i})$, \& $\mathrm{CPD}(\mathrm{j})$ and the game value $\operatorname{DDP} / \mathrm{L}(\mathrm{i}, \mathrm{j})$ if it is pure strategy game, or it shows the percentages of playing the project's duration strategies for both parties and the corresponding expected DDP/L $(\mathrm{i}, \mathrm{j})$ values.

\section{ILLUSTRATION OF A PROJECT}

a. Consider the following simple project:

\begin{tabular}{|c|c|}
\hline \multicolumn{2}{|c|}{ Table 1 } \\
\hline Activity & $\begin{array}{c}\text { Immediate } \\
\text { Predecessor }\end{array}$ \\
\hline A & -- \\
\hline B & -- \\
\hline C & A \\
\hline D & A \\
\hline E & C,B \\
\hline F & C,B \\
\hline G & D,E \\
\hline
\end{tabular}

\begin{tabular}{|c|c|}
\hline \multicolumn{2}{|c|}{ Table 2 } \\
\hline Activity & $\begin{array}{c}\text { Time } \\
\text { (months) }\end{array}$ \\
\hline A & 4 \\
\hline B & 6 \\
\hline C & 2 \\
\hline D & 6 \\
\hline E & 3 \\
\hline F & 3 \\
\hline G & 5 \\
\hline
\end{tabular}


Tables 1 and 2 show a 7-activity project. The activities $A$ through $\mathrm{G}$ are preceded by a start point and culminate with an end after steps $\mathrm{F}$ and $\mathrm{G}$ are complete. Table 1 shows the precedence of the activities and Table 2 shows the normal duration time in months. We have just completed steps 1 and 2 of the Proposed Project Management Procedure.

b. Next, we move to step 3. In step 3, we identify the crash times and the costs for normal and crashed activity times. These are outlined in Table 3. These times are given as a point estimate, so we go directly to CPM. No calculation is required for expected time or the variance. This completes step (3).

\begin{tabular}{|c|c|c|c|c|}
\hline \multicolumn{3}{|c|}{ Table 3 } & \multicolumn{2}{c|}{ Total Cost (\$000s) } \\
\hline & \multicolumn{2}{|c|}{ Time (months) } & Normal & Crash \\
\hline Activity & Normal & Crash & 50 & 70 \\
\hline A & 4 & 2 & 40 & 55 \\
\hline B & 6 & 3 & 20 & 13 \\
\hline C & 2 & 1 & 100 & 60 \\
\hline D & 6 & 4 & 50 & 25 \\
\hline F & 3 & 2 & 25 & 75 \\
\hline G & 3 & 3 & 60 & \\
\hline
\end{tabular}

c. $\quad$ Now we move to step 4, drawing the network diagram. This can be accomplished using 1 of 2 methods; i.e. arrow activity oriented network diagram (Figure 2) or node oriented network diagram (Figure 3). Either method is acceptable depending upon your personal preference.

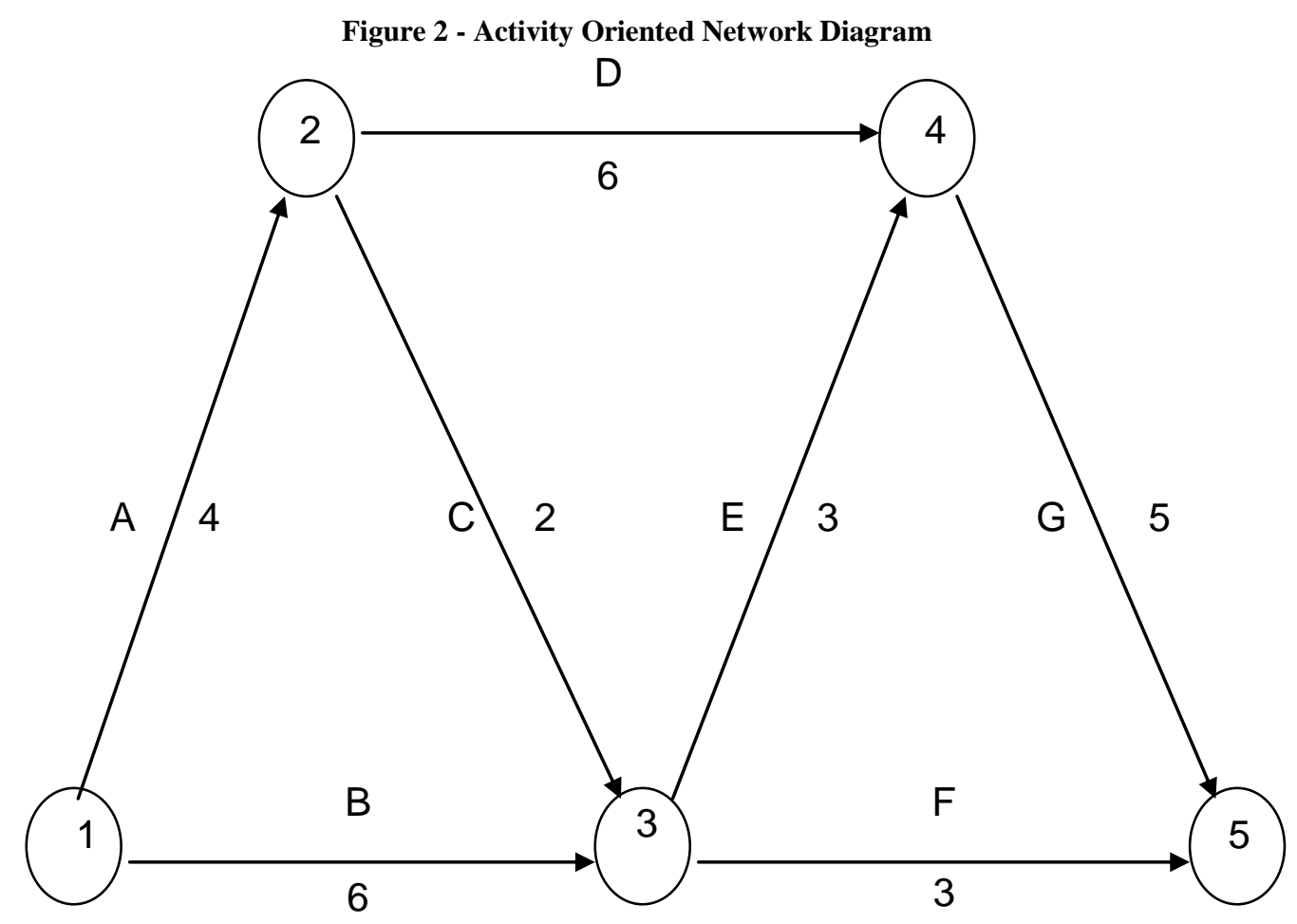


Figure 3 - Node Oriented Network Diagram

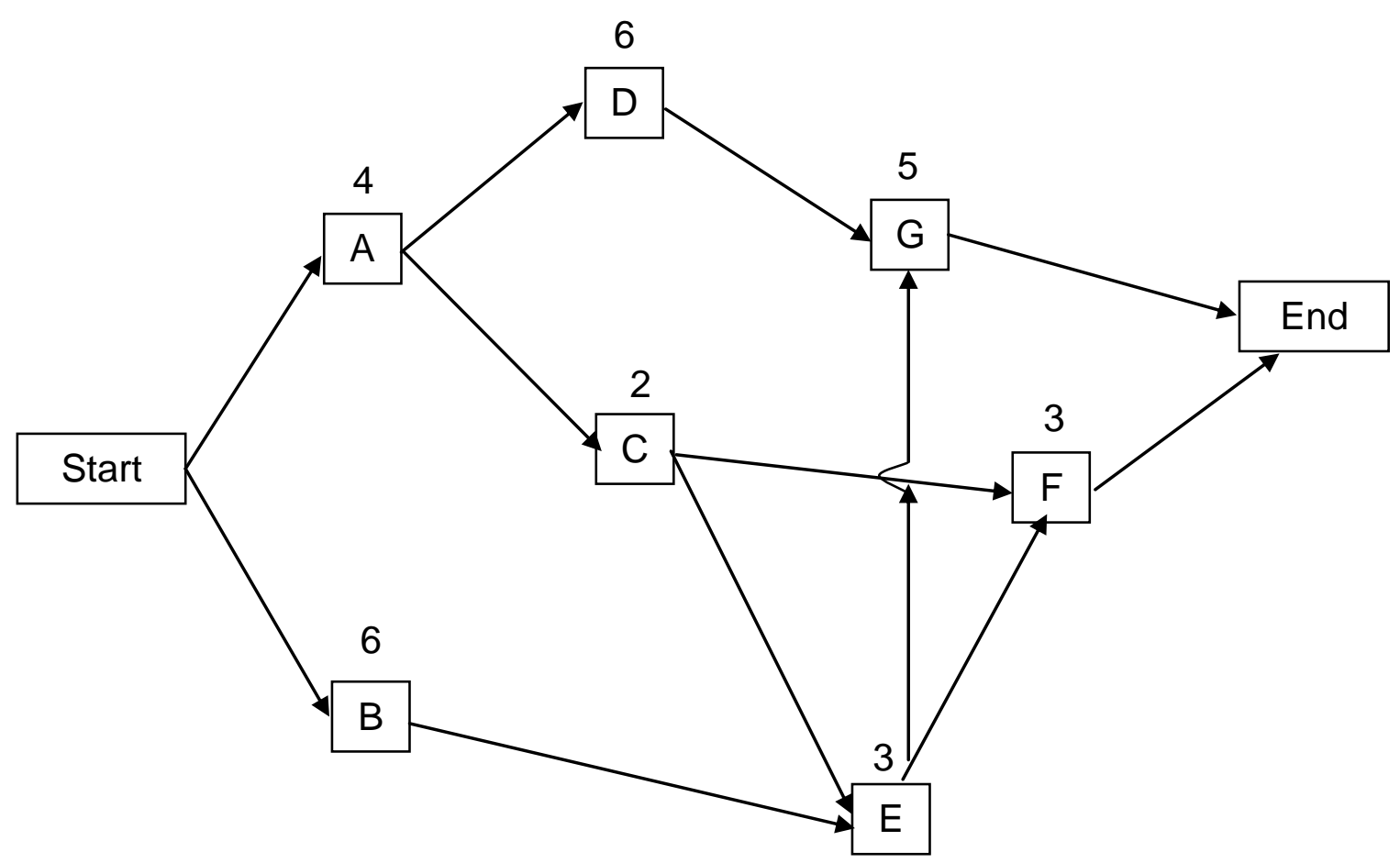

The dependencies and time for each stage of the activity oriented network diagram (CPM) or node oriented network diagram node (PERT) are available on either diagram.

c. Next are steps 5, 6, and 7. First, we must utilize a software package to compute the total time to complete the project, as well as the early and late start, early and late finish, and possible slack time for each of the activities. The DSS package "QM" was used for these computations. The input data is listed followed by the output. Activities A, B, C, D, E, F, G are activities 1, 2, 3, 4, 5, 6, and 7, respectively. Under normal conditions, the total time to complete the project is 15 months. Activities B, C, E, and F have slack time. The critical path, identified by asterisks in the output table is A D F. The QM output, or activity schedule, and critical path on the network are shown in Chart 1:

\section{Chart 1}

Program: CPM/PERT / CPM

Problem Title: Illustration without Crashing

\begin{tabular}{|c|c|c|c|}
\hline Activity & Start & End & Time \\
\hline 1 & & 2 & 4.000 \\
\hline 2 & & 3 & 6.000 \\
\hline 3 & & 3 & 2.000 \\
\hline 4 & & 4 & 6.000 \\
\hline 5 & & 4 & 3.000 \\
\hline 6 & & 5 & 3.000 \\
\hline 7 & & 5 & 5.000 \\
\hline
\end{tabular}


Chart 1 (continued)

***** Program Output *****

\begin{tabular}{|c|c|c|c|c|c|}
\hline Activity & $\begin{array}{l}\text { Earliest } \\
\text { Start }(E F)\end{array}$ & $\begin{array}{l}\text { Earliest } \\
\text { Finish(EF) }\end{array}$ & $\begin{array}{l}\text { Latest } \\
\text { Start(LF) }\end{array}$ & $\begin{array}{l}\text { Latest } \\
\text { Finish(LF) }\end{array}$ & $\begin{array}{l}\text { Slack } \\
\text { (LS-ES) }\end{array}$ \\
\hline $1 *$ & 0.000 & 4.000 & 0.000 & 4.000 & 0.000 \\
\hline 2 & 0.000 & 6.000 & 1.000 & 7.000 & 1.000 \\
\hline 3 & 4.000 & 6.000 & 5.000 & 7.000 & 1.000 \\
\hline $4 *$ & 4.000 & 10.000 & 4.000 & 10.000 & 0.000 \\
\hline 5 & 6.000 & 9.000 & 7.000 & 10.000 & 1.000 \\
\hline 6 & 6.000 & 9.000 & 12.000 & 15.000 & 6.000 \\
\hline $7 *$ & 10.000 & 15.000 & 10.000 & 15.000 & 0.000 \\
\hline
\end{tabular}

(* : Critical Path Activities)

Expected Completion Time : 15.000

$* * * * *$ End of Output $* * * * *$

e. Now we are ready to start crashing the project. This is step 8. First, we must set up the network in the QM program, CPM With Crashing. This is a repeat of the networks illustrated above in Figures 2 and 3. The QM output, or activity schedule, and critical path on the network follow in Chart 2:

\section{Chart 2}

Program: CPM/PERT / CPM With Crashing Problem Title: Crashing, O Months Crashed ***** Input Data *****

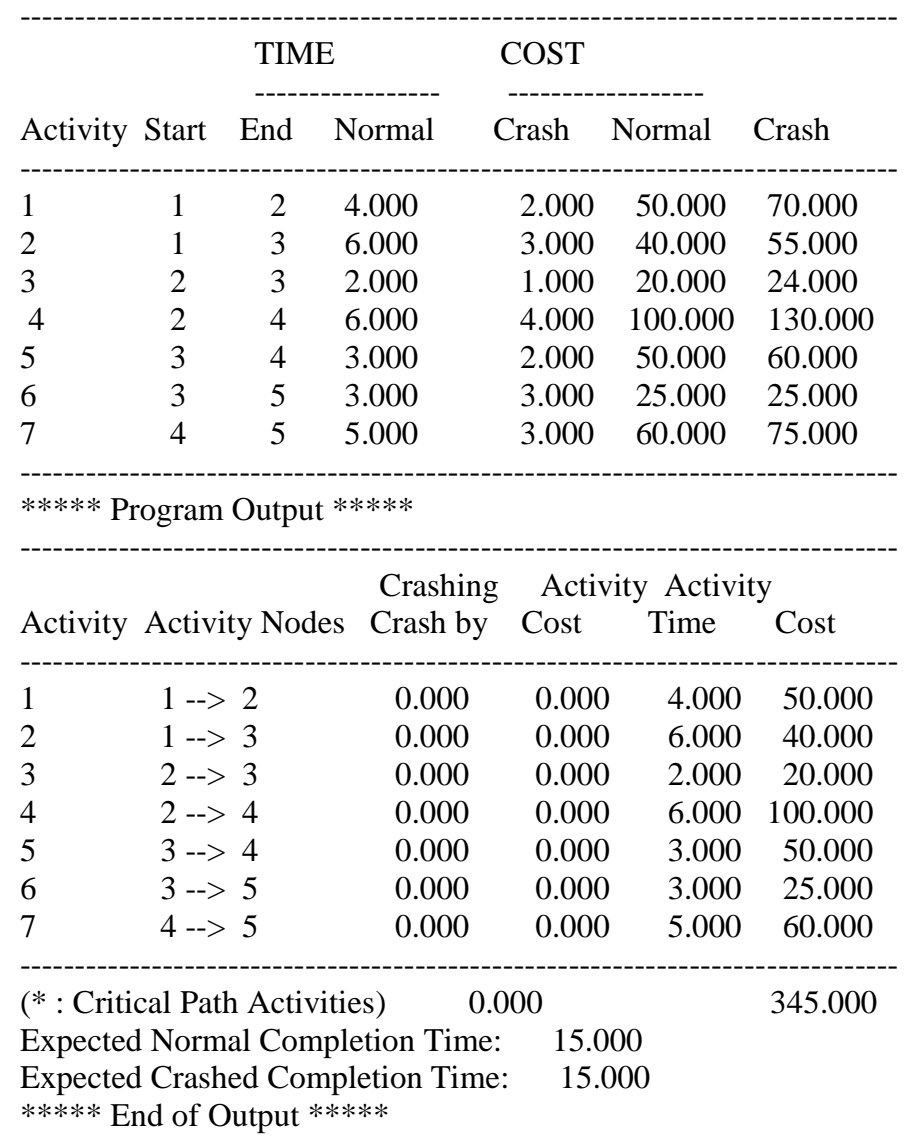


This is the first step in crashing. Note that the normal time is 15 months and the requested crash time is also 15 months. There are no activities that were crashed and the total cost is $\$ 345,000$. This established the time and cost baseline for the project under normal conditions.

Now we start crashing, beginning with a 14-month time period. Chart 3 below shows this input and output.

\section{Chart 3}

Program: CPM/PERT / CPM with Crashing

Problem Title: Crashing, 1 Month Crashed

***** Input Data $* * * * *$

\begin{tabular}{|c|c|c|c|c|c|c|}
\hline \multirow[b]{2}{*}{ Activity } & \multirow[b]{2}{*}{ Start } & \multicolumn{2}{|r|}{ TIME } & \multicolumn{2}{|c|}{ COST } & \multirow[b]{2}{*}{ Crash } \\
\hline & & End & Normal & Crash & Normal & \\
\hline 1 & 1 & 2 & 4.000 & 2.000 & 50.000 & 70.000 \\
\hline 2 & 1 & 3 & 6.000 & 3.000 & 40.000 & 55.000 \\
\hline 3 & 2 & 3 & 2.000 & 1.000 & 20.000 & 24.000 \\
\hline 4 & 2 & 4 & 6.000 & 4.000 & 100.000 & 130.000 \\
\hline 5 & 3 & 4 & 3.000 & 2.000 & 50.000 & 60.000 \\
\hline 6 & 3 & 5 & 3.000 & 3.000 & 25.000 & 25.000 \\
\hline 7 & 4 & 5 & 5.000 & 3.000 & 60.000 & 75.000 \\
\hline
\end{tabular}

***** Program Output $* * * * *$

\begin{tabular}{|c|c|c|c|c|c|}
\hline Activity & Activity Nodes & $\begin{array}{l}\text { Crashing } \\
\text { Crash by }\end{array}$ & $\begin{array}{l}\text { Activity } \\
\text { Cost }\end{array}$ & $\begin{array}{l}\text { Activity } \\
\text { Time }\end{array}$ & Cost \\
\hline $1 *$ & $1->2$ & 0.000 & 0.000 & 4.000 & 50.000 \\
\hline 2 & $1->3$ & 0.000 & 0.000 & 6.000 & 40.000 \\
\hline 3 & $2->3$ & 0.000 & 0.000 & 2.000 & 20.000 \\
\hline $4 *$ & $2->4$ & 0.000 & 0.000 & 6.000 & 100.000 \\
\hline 5 & $3->4$ & 0.000 & 0.000 & 3.000 & 50.000 \\
\hline 6 & $3->5$ & 0.000 & 0.000 & 3.000 & 25.000 \\
\hline $7 *$ & $4-->5$ & 1.000 & 7.500 & 4.000 & 67.500 \\
\hline
\end{tabular}

Expected Normal Completion Time : 15.000

Expected Crashed Completion Time : 14.000

$* * * * *$ End of Output $* * * * *$

Note that the normal time above is 15 months and the requested crash time is 14 months. The program has identified activity 7 for crashing. The total cost has risen to $\$ 352,500$, which is $\$ 7,500$ greater than the non-crashed cost. Activity 7 was chosen for this example. Why is this true? It is because activity 7 has the lowest cost per month of activities on the critical path.

Using the information provided in Table 4 below, we begin next by crashing to 13 months. 
Table 4

\begin{tabular}{|c|c|c|c|c|c|c|c|c|c|}
\hline Act. & Beg & End & $\begin{array}{c}\text { Normal } \\
\text { Months }\end{array}$ & $\begin{array}{c}\text { Crash } \\
\text { Months }\end{array}$ & Normal \$ & Crash \$ & $\begin{array}{c}\text { Months } \\
\text { Available to } \\
\text { Crash }\end{array}$ & $\begin{array}{c}\text { Total } \\
\text { Crash } \\
\text { Delta }\end{array}$ & $\begin{array}{c}\text { Crash } \\
\text { Cost Per } \\
\text { Month }\end{array}$ \\
\hline $1^{*}$ & 1 & 2 & 4 & 2 & $\$ 50$ & $\$ 70$ & 2 & $\$ 20$ & $\$ 10.0$ \\
\hline 2 & 1 & 3 & 6 & 3 & $\$ 40$ & $\$ 55$ & 3 & $\$ 15$ & $\$ 5.0$ \\
\hline 3 & 2 & 3 & 2 & 1 & $\$ 20$ & $\$ 24$ & 1 & $\$ 4$ & $\$ 4.0$ \\
\hline $4^{*}$ & 2 & 4 & 6 & 4 & $\$ 100$ & $\$ 130$ & 2 & $\$ 30$ & $\$ 15.0$ \\
\hline 5 & 3 & 4 & 3 & 2 & $\$ 50$ & $\$ 60$ & 1 & $\$ 10$ & $\$ 10.0$ \\
\hline 6 & 3 & 5 & 3 & 3 & $\$ 25$ & $\$ 25$ & 0 & $\$ 0$ & $\mathrm{~N} / \mathrm{A}$ \\
\hline $7^{*}$ & 4 & 5 & 5 & 3 & $\$ 60$ & $\$ 75$ & 2 & $\$ 15$ & $\$ 7.5$ \\
\hline
\end{tabular}

\section{Chart 4}

Program: CPM/PERT / CPM with Crashing

Problem Title: Crashing, 2 Months Crashed

\begin{tabular}{|c|c|c|c|c|c|c|}
\hline \multirow[b]{2}{*}{ Activity } & \multirow[b]{2}{*}{ Start } & \multicolumn{2}{|c|}{ TIME } & \multicolumn{2}{|c|}{ COST } & \multirow[b]{2}{*}{ Crash } \\
\hline & & End & Normal & Crash & Normal & \\
\hline 1 & 1 & 2 & 4.000 & 2.000 & 50.000 & 70.000 \\
\hline 2 & 1 & 3 & 6.000 & 3.000 & 40.000 & 55.000 \\
\hline 3 & 2 & 3 & 2.000 & 1.000 & 20.000 & 24.000 \\
\hline 4 & 2 & 4 & 6.000 & 4.000 & 100.000 & 130.000 \\
\hline 5 & 3 & 4 & 3.000 & 2.000 & 50.000 & 60.000 \\
\hline 6 & 3 & 5 & 3.000 & 3.000 & 25.000 & 25.000 \\
\hline 7 & 4 & 5 & 5.000 & 3.000 & 60.000 & 75.000 \\
\hline
\end{tabular}

$* * * * *$ Program Output $* * * * *$

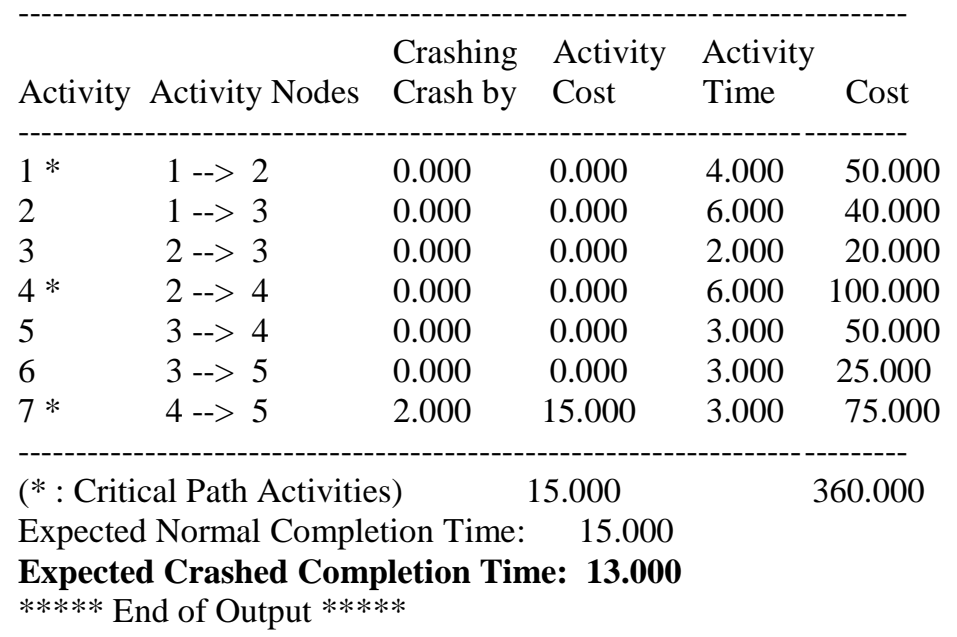

As seen in Chart 4 above, the program has identified activity 7 again for crashing at a total cost of $\$ 360,000$. The critical path has not changed and activity 7 has the lowest per month cost on the critical path. Now repeat the process till we reach the infeasible solution. 
Now we move to 8 months and look below at Chart 5 for software output.

\section{Chart 5}

Program: CPM/PERT / CPM with Crashing

Problem Title: Crashing, 7 Months Crashed

\begin{tabular}{|c|c|c|c|c|c|c|}
\hline \multirow[b]{2}{*}{ Activity } & \multirow[b]{2}{*}{ Start } & \multicolumn{2}{|c|}{ TIME } & \multicolumn{2}{|c|}{ COST } & \multirow[b]{2}{*}{ Crash } \\
\hline & & End & Normal & Crash & Normal & \\
\hline 1 & 1 & 2 & 4.000 & 2.000 & 50.000 & 70.000 \\
\hline 2 & 1 & 3 & 6.000 & 3.000 & 40.000 & 55.000 \\
\hline 3 & 2 & 3 & 2.000 & 1.000 & 20.000 & 24.000 \\
\hline 4 & 2 & 4 & 6.000 & 4.000 & 100.000 & 130.000 \\
\hline 5 & 3 & 4 & 3.000 & 2.000 & 50.000 & 60.000 \\
\hline 6 & 3 & 5 & 3.000 & 3.000 & 25.000 & 25.000 \\
\hline 7 & 4 & 5 & 5.000 & 3.000 & 60.000 & 75.000 \\
\hline
\end{tabular}

***** Program Output *****

ERROR ! - illegal expected project time

Expected project time must be less than or equal to the project time without crashing and greater than or equal to the minimum possible project time.

Project time without crashing $=15$

Minimum possible project time $=9$

Input value of expected project time $=\quad 8$

$* * * * *$ End of Output $* * * * *$

This is the final step in crashing. The solution is 9 months because 8 months is not feasible as a requested possible solution for the given conditions.

There is one last point to analyze. Suppose we run crash times through the CPM without crashing the program in QM, we get the following output as seen in Chart 6.

\section{Chart 6}

Program: CPM/PERT / CPM

Problem Title: Illustration without Crashing

\begin{tabular}{cccc}
$* * * * *$ & Input Data $* * * * *$ \\
\hline Activity & Start & End & Time \\
\hline---- & 2.000 \\
1 & 1 & 2 & 3.000 \\
2 & 1 & 3 & 1.000 \\
3 & 2 & 3 & 4.000 \\
4 & 2 & 4 & 2.000 \\
5 & 3 & 4 & 3.000 \\
6 & 3 & 5 & 3.000 \\
7 & 4 & 5 &
\end{tabular}




\section{Chart 6 (continued)}

$\begin{array}{llllll}* * * * * & \text { Program Output } * * * * * & & & \\ - & \text { Earliest } & \text { Earliest } & \text { Latest } & \text { Latest } & \text { Slack } \\ \text { Activity } & \text { Start(EF) } & \text { Finish(EF) } & \text { Start(LF) } & \text { Finish(LF) } & \text { (LS-ES) } \\ ---{ }^{*} & 0.000 & 2.000 & 0.000 & 2.000 & 0.000 \\ 2 & 0.000 & 3.000 & 1.000 & 4.000 & 1.000 \\ 3 & 2.000 & 3.000 & 3.000 & 4.000 & 1.000 \\ 4 * & 2.000 & 6.000 & 2.000 & 6.000 & 0.000 \\ 5 & 3.000 & 5.000 & 4.000 & 6.000 & 1.000 \\ 6 & 3.000 & 6.000 & 6.000 & 9.000 & 3.000 \\ 7 * & 6.000 & 9.000 & 6.000 & 9.000 & 0.000\end{array}$

(*: Critical Path Activities)

Expected Completion Time: 9.000

$* * * * *$ End of Output $* * * * *$

Note that we again get 9 months as the optimal solution, but we crashed one additional month in activity 5, which was unnecessary. If we would have used the given activity's fully crashed times, we would have incurred an additional $\$ 10,000$ in cost. You must be sure to analyze crashing properly to determine if crashing all activities is necessary (see Table 5 below).

Table 5

\begin{tabular}{|c|c|c|c|c|c|}
\hline Activity & Normal Months & Crash Months & Crash \$ & $\begin{array}{c}\text { 9 Month Optimal } \\
\text { Solution Months }\end{array}$ & $\begin{array}{c}\text { 9 Month Optimal } \\
\text { Solution \$ }\end{array}$ \\
\hline 1 & 4 & 2 & $\$ 70$ & 2 & $\$ 70$ \\
\hline 2 & 6 & 3 & $\$ 55$ & 3 & $\$ 55$ \\
\hline 3 & 2 & 1 & $\$ 24$ & 1 & $\$ 24$ \\
\hline 4 & 6 & 4 & $\$ 130$ & 4 & $\$ 130$ \\
\hline $\mathbf{5}$ & $\mathbf{3}$ & $\mathbf{2}$ & $\$ \mathbf{6 0}$ & 3 & $\mathbf{\$ 5 0}$ \\
\hline 6 & 3 & 3 & $\$ 75$ & 3 & $\$ 25$ \\
\hline 7 & 5 & & $\$ 439$ & & $\$ 75$ \\
\hline Total Cost & & & & $\$ 429$ \\
\hline
\end{tabular}

This completes step 8 of the Proposed Project Management Procedure.

f. Next is step 9 - preparation of the strategic decision table (Table 6).

Table 6

\begin{tabular}{|c|c|c|c|}
\hline \multicolumn{4}{|c|}{ Illustration Strategic Decision Table } \\
\hline Time & Direct Cost & Indirect Cost & Total Cost \\
\hline 15 & $\$ 345,000$ & $\$ 157,500$ & $\$ 502,500$ \\
\hline 14 & $\$ 352,000$ & $\$ 147,000$ & $\$ 499,000$ \\
\hline 13 & $\$ 360,000$ & $\$ 136,500$ & $\$ 496,500$ \\
\hline 11 & $\$ 370,000$ & $\$ 126,000$ & $\$ 496,000$ \\
\hline 10 & $\$ 385,000$ & $\$ 115,500$ & $\$ 500,500$ \\
\hline 9 & $\$ 405,000$ & $\$ 105,000$ & $\$ 510,000$ \\
\hline
\end{tabular}


Indirect cost is related to the amount of time to administer the project and overhead spread to the number of project months. Indirect costs will get lower as the project time lessens. We know from the crashing analysis that direct cost will rise as the project time shrinks. This gives us a "U" shaped total cost curve (Figure 4).

Figure 4

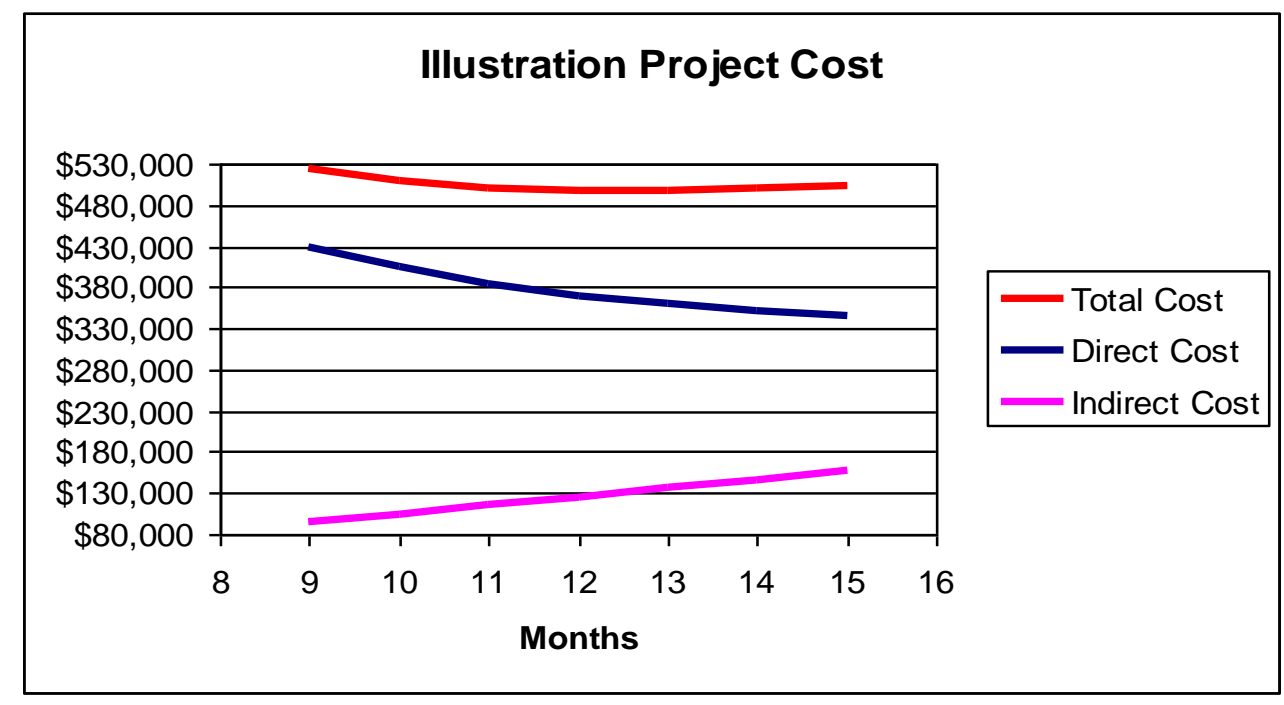

g. Finally step (10) - the decision. Let's assume the following situation:

- Our firm is responding to a request for proposal (RFP) for a project.

- The RFP states that the project shall be completed in a minimum of 15 months, with alternate proposals accepted for a smaller amount of time.

- Our bid markup on total cost is $10 \%$.

- We are not the only bidder.

Consider the decision table with profit information added (Table 7).

Table 7

\begin{tabular}{|c|c|c|c|c|c|c|c|}
\hline \multicolumn{9}{|c|}{ Strategic Decision Table with Profit Information Added } \\
\hline Time & Direct Cost & Indirect Cost & Total Cost & Profit @ 10\% & Bid Price & $\begin{array}{c}\text { Alternate Bid } \\
\text { Price }\end{array}$ & $\begin{array}{c}\text { Additional } \\
\text { Profit }\end{array}$ \\
\hline 15 & $\$ 345,000$ & $\$ 157,500$ & $\$ 502,500$ & $\$ 50,250$ & $\$ 552,750$ & $\$ 552,750$ & $\$ 0$ \\
\hline 14 & $\$ 352,000$ & $\$ 147,000$ & $\$ 499,000$ & $\$ 49,900$ & $\$ 548,900$ & $\$ 552,750$ & $\$ 3,850$ \\
\hline 13 & $\$ 360,000$ & $\$ 136,500$ & $\$ 496,500$ & $\$ 49,650$ & $\$ 546,150$ & $\$ 552,750$ & $\$ 6,600$ \\
\hline 12 & $\$ 370,000$ & $\$ 126,000$ & $\$ 496,000$ & $\$ 49,600$ & $\$ 545,600$ & $\$ 552,750$ & $\$ 7,150$ \\
\hline 11 & $\$ 385,000$ & $\$ 115,500$ & $\$ 500,500$ & $\$ 50,050$ & $\$ 550,550$ & $\$ 552,750$ & $\$ 2,200$ \\
\hline 10 & $\$ 405,000$ & $\$ 105,000$ & $\$ 510,000$ & $\$ 51,000$ & $\$ 561,000$ & $\$ 561,000$ & $\$ 0$ \\
\hline 9 & $\$ 429,000$ & $\$ 94,500$ & $\$ 523,500$ & $\$ 52,350$ & $\$ 575,850$ & $\$ 575,850$ & $\$ 0$ \\
\hline
\end{tabular}

Our firm has a couple of options. If the firm is confident it would not be underbid, it could propose the alternate bid price for completion periods 11-15 and bid the higher prices for months 10 and 11. The firm would reap additional profits if the buyer accepted the proposal for months 11,12,13, or 14. If competition is tight and our firm needed the work, we could propose the bid price of $\$ 545,600$ (the month 12 bid price) for months $12,13,14$, and 15 and the higher bid prices for months 9,10 , and 11 . If award was made at month 14, we would complete the 
project in 12 months in order to minimize our total cost and maximize our profit. We would have a happy customer, assuming the project was completed two months early and would have built in two months of slack. If the project takes 14 months to complete, our penalty would not be under a formal contract penalty clause with an exorbitant cost. Our "informal" penalty would be $\$ 3,000$ for the increased costs (direct and indirect). There are other bid possibilities depending on the competitive situation and any unique capabilities possessed by our firm. The strategic tables $(8,9$ and 10) show the other possibilities along with priorities to help the decision-makers respond favorably according to the market competitors and other contingencies. However, these tables are known only to the bidder to give them an edge over project owners and market's competitors.

Looking at Table 8 below, DDP/L $(4,1)$ tells the decision-maker that he is willing to reduce his project cost up to $\$ 27,500$ if the contract owner is willing to relax the project duration from nine months to 12 months. Table 9 is Table 8 without losses. That is, negative values of $\operatorname{DDP} / \mathrm{L}(\mathrm{i}, \mathrm{j})$ are dropped from Table 9 due to the fact that the strategies would reduce the mark-up profit by the shown amount. Table 8 shows the priorities of the project's duration bidding strategies in descending order of $\mathrm{DDP} / \mathrm{L}(\mathrm{i}, \mathrm{j})$. According to Table 5 , DDP/L $(4,1)$ has a value of $\$ 27,500$. Since this value is the highest in the table, it is given priority \#1. The bidder has a wide range of extra profits over and above the mark-up profit to deal with in bidding.

Table 8

\begin{tabular}{|c|c|c|c|c|c|c|c|c|c|c|}
\hline \multicolumn{11}{|c|}{$\begin{array}{c}\text { Contact's Project Time, } \\
\text { CPT ( j ) }\end{array}$} \\
\hline \multirow{10}{*}{ 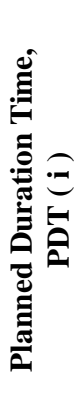 } & . & $\bar{j}$ & 1 & 2 & 3 & 4 & 5 & 6 & 7 & \multirow{10}{*}{ 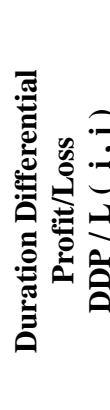 } \\
\hline & $\mathrm{i}$ & Project Time & 9 & 10 & 11 & 12 & 13 & 14 & 15 & \\
\hline & 1 & 9 & 0 & -13500 & -23000 & -27500 & -27000 & -24500 & -21000 & \\
\hline & 2 & 10 & 13500 & 0 & -9500 & -14000 & -13500 & -11000 & -7500 & \\
\hline & 3 & 11 & 23000 & 9500 & 0 & -3500 & -4000 & -1500 & 2000 & \\
\hline & 4 & 12 & 27500 & 14000 & 4500 & 0 & 500 & 3000 & 6500 & \\
\hline & 5 & 13 & 27000 & 13500 & 4000 & -500 & 0 & 2500 & 6000 & \\
\hline & 6 & 14 & 24500 & 11000 & 1500 & -3000 & -2500 & 0 & 3500 & \\
\hline & 7 & 15 & 21000 & -7500 & -2000 & -6500 & -6000 & -3500 & 0 & \\
\hline & \multicolumn{9}{|c|}{$\begin{array}{c}\text { Duration Differntial Profit /Loss } \\
\text { DD P/L ( } \mathbf{i}, \mathbf{j})\end{array}$} & \\
\hline
\end{tabular}

Submit Table 8 to the DSS's theory of games sub-routine and the output shows that the table is a pure strategy game; it is a zero-sum game - the best combination of $\operatorname{PPD}(\mathrm{i}), \mathrm{CPD}(\mathrm{j})$ and the game value $\mathrm{DDP} / \mathrm{L}(\mathrm{i}, \mathrm{j})$. If it is not a pure strategy game, it shows the percentages of playing the project's duration strategies for both parties and the corresponding expected DDP/L $(\mathrm{i}, \mathrm{j})$ values.

The above illustration results for optimal strategies for both parties are:

$\mathrm{PDT}(12), \mathrm{CPT}(12), \& \mathrm{DDP} / \mathrm{L}(12,12)=0$

Table 9

\begin{tabular}{|c|c|c|c|c|c|c|c|c|c|c|}
\hline \multicolumn{11}{|c|}{$\begin{array}{c}\text { Contact's Project Time, } \\
\text { CPT }(\mathbf{j})\end{array}$} \\
\hline \multirow{10}{*}{ حَ } & & $\mathrm{j}$ & 1 & 2 & 3 & 4 & 5 & 6 & 7 & \multirow{10}{*}{ 玨 } \\
\hline & $\mathrm{i}$ & Project Time & 9 & 10 & 11 & 12 & 13 & 14 & 15 & \\
\hline & 1 & 9 & 0 & & & & & & & \\
\hline & 2 & 10 & 13500 & 0 & & & & & & \\
\hline & 3 & 11 & 23000 & 9500 & 0 & & & & 2000 & \\
\hline & 4 & 12 & 27500 & 14000 & 450 & 0 & 500 & 3000 & 6500 & \\
\hline & 5 & 13 & 27000 & 13500 & 4000 & & 0 & 2500 & 6000 & \\
\hline & 6 & 14 & 24500 & 11000 & 150 & & & & 3500 & \\
\hline & 7 & 15 & 21000 & & & & & & 0 & \\
\hline & \multicolumn{9}{|c|}{$\begin{array}{c}\text { Duration Differntial Profit /Loss } \\
\text { DD P/L }(\mathbf{i}, \mathbf{j})\end{array}$} & \\
\hline
\end{tabular}


Table 10

\begin{tabular}{|c|c|c|c|c|c|c|c|c|c|c|}
\hline \multicolumn{11}{|c|}{$\begin{array}{c}\text { Contact's Project Time, } \\
\text { CPT }(\mathbf{j})\end{array}$} \\
\hline \multirow{10}{*}{ 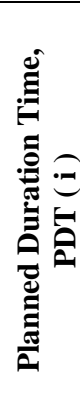 } & & $\mathrm{j}$ & 1 & 2 & 3 & 4 & 5 & 6 & 7 & \multirow{10}{*}{ 五 } \\
\hline & $\mathrm{i}$ & Project Time & 9 & 10 & 11 & 12 & 13 & 14 & 15 & \\
\hline & 1 & 9 & 20 & & & & & & & \\
\hline & 2 & 10 & 7 & 20 & & & & & & \\
\hline & 3 & 11 & 4 & 9 & 20 & & & & 17 & \\
\hline & 4 & 12 & 1 & 6 & 12 & 20 & 19 & 15 & 10 & \\
\hline & 5 & 13 & 2 & 7 & 13 & & 20 & 16 & 11 & \\
\hline & 6 & 14 & 3 & 8 & 18 & & & 20 & 14 & \\
\hline & 7 & 15 & 5 & & & & & & 20 & \\
\hline & \multicolumn{9}{|c|}{$\begin{array}{c}\text { Duration Differntial Profit /Loss } \\
\text { DD P/L ( } \mathbf{i}, \mathbf{j})\end{array}$} & \\
\hline
\end{tabular}

\section{CONCLUSION}

The illustrations demonstrate that the optimal solution for Project Management is not necessarily the shortest amount of time of the least "direct" project cost solution. There are possible hidden costs to consider, such as unnecessarily crashing activities or unallocated indirect costs that must be considered to identify the total project cost. These data can provide a wealth of information to managers and should be utilized to determine the project duration strategic decision table. This technique can be utilized on projects internal to the firm or in the bidding process.

\section{AUTHOR INFORMATION}

Dr. Ali Alli specializes in production and quality control, optimization techniques of distribution, project management and managerial decision making. He has worked in area recreational facilities in southeast Texas, optimization of workforce personnel at the King Abdulaziz Airport in Saudi Arabia and in projects related to controlling labor costs at CMI in Oklahoma. Professor Alli is a registered professional engineer. His teaching and research activities span a period of over 35 years. He is Professor Emeriti at Oklahoma City University

Dr. David L. May spent more than 16 years in the oil and natural gas industry prior to receiving his Ph.D. in economics from Florida State University. He consults regularly with law firms, regulatory agencies, oil industry firms, and state and local government agencies. Professor May is department chair in economics and finance at Oklahoma City University and is the Henry J. Freede, MD Endowed Chair in Teaching excellence there.

\section{REFERENCES}

1. Anderson, D., Sweeney, D., \& Williams, T. (1997). An Introduction to Management Science (8th ed.). West Publishing Co.

2. Gupta, Shiv K., \& Gozzolino, John (1975). Fundamentals of Operations Research for

Management. Holden-Day Publishing Co.

3. Lee \& Shim (1986). Micro Management Science. Wm C. Brown Publishers.

4. Taha, Hawdy A. (1987). Operations Research (4th ed.). McMillian Publishing Co.

5. Turbin \& Meredith (1988). Fundamentals of Management Science (4th ed.). Business Publications Inc.

6. Wagner (1969). Principles of Operations Research (2nd ed.). Prentice Hall Inc. 